\title{
Estado y modernización: quince tesis $y$ un corolario para México
}

Henio Millán Valenzuela*

\section{Abstract}

The paper argues that after the depletion of the state interventionist model, related to a closed economy and a corporative scheme of social participation, the state modernization in Mexico must tend towards a "third way", not only because of ideological reasons facing the free market, but because of the important presence of collective actors who do not follow the logic of that modernization, as well as due to the great influence of structural disparities on Mexican society. Is in this sense that modernization should be moving between the coordinates imposed by the imperative of introducing Mexico into the international market, and those emerging from its structural and historical specificity.

Keywords: State, modernization, historical specificities, alternative ways, social and economical policies.

Resumen

El artículo pretende demostrar que tras el agotamiento del modelo de intervencionismo estatal, asociado a una economía cerrada y a un esquema corporativo de participación social, la modernización del Estado mexicano tiene que optar por una "tercera vía” no sólo por razones ideológicas frente al libre mercado,

*El Colegio Mexiquense, correo-e: hmillan@cmq.edu.mx.

Economía, Sociedad y Territorio, vol. II, núm. 8, 2000, 721-756. 
sino por la significativa presencia de los actores colectivos, que no responden a la lógica de esa modernización, y por la enorme influencia de las disparidades estructurales sobre la sociedad mexicana. En este sentido, esa modernización debe moverse entre las coordenadas que impone la necesidad de insertar a México en el mercado internacional y las que derivan de su especificidad histórica y estructural.

Palabras clave: Estado, modernización, circunstancias históricas, vías alternativas, política social y política económica.

\section{Introducción $^{1}$}

El Estado ha sido un referente obligado en la historia del capitalismo occidental: su nacimiento y desarrollo han corrido al parejo de las actividades económicas organizadas en función de la ganancia; pero el grado de injerencia estatal en estas actividades ha variado en el tiempo, en función de necesidades y particularidades históricas, de pugnas ideológicas y de la capacidad de los distintos grupos para traducir e imponer sus intereses particulares como interés general. La forma en que estos tres elementos se conjugan ha cimentado en el desarrollo social un ciclo de intervencionismo estatal que, en cada una de sus fases, activa racionalizaciones elaboradas y propuestas políticas sobre el papel que el Estado debe jugar en la organización y en el proceso económico.

La crisis de 1929 vino a dar al traste con esta concepción liberal. La política que recluía al Estado a su mínima expresión (el Estado-gendarme) tropezó con la realidad contundente del desempleo masivo y —aún más- con la ausencia de mecanismos de mercado capaces de restituir el equilibrio en las esferas laborales. La racionalización de este funcionamiento corrió a cargo de la corriente keynesiana, que fundó la legitimación de un nuevo intervencionismo estatal enfocado a mantener o impulsar los niveles de actividad económica y de empleo mediante políticas fiscales y monetarias capaces de compensar las insuficiencias de la demanda agregada y de la lógica pura del mercado. El bienestar dejaba de ser un asunto individual para pasar a ser una responsabilidad del Estado. Este paradigma imperó durante la posguerra hasta la crisis global del capitalismo en los años setenta. Bajo sus auspicios la mayoría de las economías registraron crecimientos notables, que fueron acompañados — sobre todo en las

${ }^{1}$ Agradezco los comentarios de los dos dictaminadores anónimos. 
desarrolladas - de sensibles mejorías en el bienestar social; pero el abuso de este esquema condujo a una crisis de ese tipo de Estado, el cual mostró claramente su disfuncionalidad para encarar los retos de una economía más globalizada y, por tanto, más dependiente de la evolución de la competitividad.

La acertada crítica al Estado de Bienestar acarreó una prescripción que apuntaba hacia la restitución del mercado como mecanismo eficiente de la asignación de los recursos; pero también a la reinstalación de la iniciativa individual como pivote exclusivo del progreso material. El neoliberalismo se apoderó de las esferas académicas, financieras, internacionales y gubernamentales, al tiempo que cancelaba alternativas políticas e históricas que, hasta entonces, se antojaban más viables para humanizar la actividad económica en su dimensión social. Un nuevo totalitarismo ideológico emergía bajo el ropaje de otro pensamiento único $(\mathrm{Bu}-$ ttiglione, 1999). Tras el fracaso estrepitoso del socialismo real y el repliegue de un Estado fincado en visiones socialdemócratas, la racionalidad del mercado fue esgrimida como la única salida del laberinto en el que la Historia (con mayúsculas) había enredado al hombre.

Sin embargo, el desencanto no se hizo esperar: aunque las políticas neoliberales que siguieron los gobiernos occidentales acertaron al introducir y fomentar cambios ineludibles en el orden económico, la reestructuración acarreó ajustes que han afectado negativamente el bienestar: el desmantelamiento de los sistemas de seguridad social aumentó el grado de indefensión de la gente ante eventos desfavorables de la economía; los avances en la estabilización macroeconómica, en la organización empresarial y el campo tecnológico han asolado el mundo laboral, que zozobra entre el desempleo masivo, la precarización del trabajo y una tendencia muy acentuada hacia obsolescencia de los conocimientos y habilidades de la mano de obra, que se despliega en una época en que, paradójicamente, tales atributos se han convertido en los factores más importantes de la competitividad (Thurow, 1992; Dertouzos, 1993).

En consecuencia, el mundo de las ideas y el de la política debaten con el afán de encontrar respuestas intermedias. México no ha estado exento de ese debate: la promesa incumplida por las reformas estructurales emprendidas desde la primera mitad de los ochenta ha cimentado la creencia cada vez más fuerte de que el aumento de la pobreza y la desigualdad, así como la descomposición del orden social, no son costos temporales de un futuro 
mejor, sino la forma de operación inherente al neoliberalismo, cuando el dominio del mercado se instala en un contexto humano signado por la heterogeneidad estructural. El desencanto ha invocado voces restauradoras que apelan omnipresencia estatal, asociada a un esquema autoritario que se extingue ante el avance de las fuerzas democráticas; pero también ha intensificado la defensa de quienes se han beneficiado, en el terreno económico y político, de la mecánica neoliberal. Para éstos los descalabros que han resentido los más débiles son sólo sacrificios que deben esperar su debida recompensa, que sólo podrá materializarse en la medida en que maduren los cambios y México avance hacia las reformas de segunda generación.

La intervención del Estado en la economía mexicana ha sido punto de referencia para dividir, engañosamente, a las fuerzas políticas conservadoras de las progresistas. El artificio proviene más de una visión prejuiciada, que del análisis de las capacidades del Estado y del impulso privado para trabajar a favor del progreso material y espiritual de los mexicanos y, en especial, de las necesidades históricas que empujaron a nuestro país a adoptar una u otra modalidad de intervención estatal. En las líneas siguientes se pretende abordar este enfoque para esclarecer el significado del agotamiento de una forma de intervención estatal que fue cimentada en una sociedad nutrida de actores e identidades colectivas, pero que hoy debe abrir el paso a otras en las que los individuos cobran un mayor peso en los procesos económicos y sociales, y los ciudadanos son los que dan el tono a la vida política mexicana.

Se pretende demostrar que, más allá de los abusos, el reciente intervencionismo estatal fue un modelo que, después de un éxito relativo, se agotó hasta tal punto que su restauración, como pretenden algunos, es absolutamente inviable. Pero también, que el agotamiento de esa forma de intervención estatal deja en la agenda tareas que no puede sortear la lógica pura neoliberal. Ésta prescribe la puesta en marcha de modificaciones ineludibles para la viabilidad nacional en un escenario irreversiblemente globalizado; pero al mismo tiempo erige obstáculos insalvables para que tal viabilidad, de materializarse, pueda traducirse en mayor bienestar y en un país socialmente más cohesionado, dos rasgos centrales que debe encarar una nueva definición del papel del Estado en la economía. 


\section{México: las coordenadas estructurales de la nueva intervención estatal}

El primer día de septiembre de 1982, el Ejecutivo Federal envió al Congreso una iniciativa tendiente a nacionalizar los activos de la banca mexicana. Por las reacciones que suscitó, tal medida marcó de forma elocuente el límite de la expansión del Estado en la economía. A diferencia de los anteriores actos de expropiación —señaladamente, la petrolera-, el retiro de la concesión de los servicios bancarios provocó el rechazo generalizado y un consenso creciente en torno al desatino de esa disposición. El sistema político exhibía el grado de discrecionalidad y de arbitrariedad que podía alcanzar un presidencialismo sin contrapesos efectivos, a pesar de que la sociedad mexicana había experimentado transformaciones sustanciales que apuntaban hacia una vida política más participativa y hacia la necesidad de desterrar las acciones de gobierno de corte unilateral. Sociedad y Estado habían tomado senderos distintos y cada vez más distantes: la legitimidad debía ser reconstruida por un nuevo pacto social, que en el fondo es el sustento de toda gestión estatal.

La respuesta neoliberal fue un intento inmediato por construir ese pacto. En su afán modernizador, pretendió actualizar el ser nacional a un patrón universal despojado de las particularidades culturales, que no siempre armonizan con la racionalidad instrumental que tal patrón necesita para funcionar. El progreso debía asumir el referente que aportan las sociedades occidentales avanzadas, mientras el pasado se convertía en un error que nunca debe repetirse. Por tal razón, entrañaba un conjunto de rupturas históricas con elementos que son todavía consustanciales a la identidad nacional, así como un atentado contra múltiples vínculos de solidaridad que el pueblo mexicano tejió en el sinuoso camino para constituirse como nación. Las fuerzas portadoras de esa tradición contravienen hoy los avances que en materia de modernización necesita nuestro país, porque ésta amenaza con excluir a grandes contingentes de la población y con desmantelar formas de vida que han sobrevivido gracias a la protección estatal.

La activación del Estado como protagonista social debe ser juzgada a la luz de un proyecto nacional incluyente, en un contexto donde la pluralidad no sólo se manifiesta en la plataforma de las ideas y de las opciones políticas, sino en formas de vida diversas. La exclusión de esas fuerzas ha sido el principal nutriente de la crisis de legitimidad que vive el modelo neoliberal y 
la razón de fondo del carácter efímero del pacto social en el que pretendió reposar.

En este sentido, México se encuentra en la encrucijada de configurar un pacto distinto que sustente en el largo plazo la operación social y las perspectivas de desarrollo. Para que sea posible, el acuerdo nacional debe instaurar la acción modernizadora como tendencia central, pero suficientemente acotada para evitar que su desbordamiento derive en la exclusión de agentes sociales a quienes el proceso modernizador les resulta ajeno, sino no es que antagónico, en virtud de sus formas de vida comunitaria o de su situación de desventaja original en la mecánica de competencia, inherente a tal proceso.

Desde otra perspectiva, tal exigencia -modernización incluyente y plural— demanda la construcción de un nuevo papel para el Estado, a partir del reconocimiento de tres hechos irreversibles e ineludibles: a) el agotamiento del modelo de intervención estatal que prevaleció desde los años treinta; b) la inviabilidad política del modelo neoliberal, en virtud de su incapacidad para mantener la cohesión social e impulsar el bienestar, y c) la necesidad ineludible de inserción en el mercado internacional. Tales elementos aportan las coordenadas en las que deberán desplegarse los esfuerzos para definir una gestión estatal que responda, simultáneamente, al actual dilema histórico mexicano: universalidad y particularidad nacional.

\section{El agotamiento del modelo de intervención estatal}

El crecimiento de la economía mexicana muestra varios rasgos estructurales que la alejan de la forma en que operan los mercados clásicos. La desintegración del aparato productivo, por ejemplo, imposibilita que la inversión privada pueda, por la dinámica propia del mercado, continuar ininterrumpidamente sin una política económica de largo plazo. Por carecer de un sector que produzca con suficiencia los bienes de capital, una buena parte de la inversión debe realizarse mediante importaciones. La consecuencia es doble: por un lado el crecimiento económico depende crucialmente de la disponibilidad de divisas (Tavares, 1980; Rodríguez, 1980); por el otro, la fuga del gasto en inversión hacia el exterior impide activar la demanda interna necesaria para traducir la capacidad productiva potencial en producción efectiva, al tiempo que abate la rentabilidad esperada de los nuevos bienes de capital. Esta deficiencia estructural imprime a la inver- 
sión una naturaleza autoderrotable (Casar, 1985 y 1986) que está ausente en los razonamientos neoliberales.

Mientras duró, la política de sustitución de importaciones revirtió este carácter autoderrotable y permitió la expansión prácticamente continua de la inversión y del producto durante las tres décadas siguientes a 1940 (Millán, 1998). Cuando se agota el proceso de sustitución de importaciones, vuelve a emerger el obstáculo al crecimiento que deriva del carácter desintegrado del aparato productivo. ${ }^{2}$ Este resurgimiento es la base de las crisis recurrentes que, con excepción de la de 1994, experimentó la economía mexicana desde los años setenta, así como de los estrechos márgenes y contradicciones frecuentes de la política económica, que no por ello estuvo exenta de errores que acarrearon efectos considerables.

La política económica enfrentó, entonces, la extenuación de las fuentes endógenas del crecimiento. Era la hora de abandonar el modelo de desarrollo a través del impulso exclusivo al mercado interno y de emprender reformas tendientes a orientar el aparato productivo hacia el exterior. En lugar de encaminar la política de desarrollo hacia esta dirección, el gobierno cedió ante la necesidad política de reforzar sus tradicionales bases de apoyo —deterioradas por una oleada de movimientos populares, que van desde la protesta ferrocarrilera hasta la insurgencia estudiantil de 1968 - y optó por prolongar la vía interna con manipulaciones fiscales de la demanda agregada.

Sin embargo, el uso excesivo del gasto y el déficit públicos para estimular la actividad económica se convirtió en un elemento generador de desequilibrios, sobre todo en el sector externo. Ante el agotamiento de la sustitución de importaciones, el gasto público aumentaba y crecía la economía; pero este comportamiento se reflejaba en déficit crecientes en las finanzas públicas y, por este conducto, en el sector externo. Para aliviar la situación, las autoridades se veían obligadas a modificar abruptamente el tipo de cambio y a emprender una política fiscal y monetaria restrictiva, que acababa por sumir al país en una crisis. Una vez que el sector externo presentaba signos de mejoría, el gasto público retomaba su tendencia al crecimiento y se repetía la secuela

${ }^{2}$ El agotamiento del proceso de sustitución de importaciones puede ser ubicado en el año de 1971, cuando el coeficiente de sustitución —definido como la participación de las importaciones en la oferta- detiene el descenso iniciado en los años cuarenta. A partir de entonces, este indicador inicia un comportamiento errático hasta 1985, cuando comienza a mostrar el comportamiento contrario: el de desustitución de importaciones (Millán, 1998). 
de crecimiento, desequilibrio externo, devaluación y política económica restrictiva. El "arranque y freno" se constituyó en el rasgo más sobresaliente del comportamiento económico, pero con una agravante adicional: los periodos de auge eran cada vez más efímeros, y las crisis, más frecuentes y más severas.

El carácter espasmódico del crecimiento económico de la economía mexicana fue la consecuencia de no haber introducido a tiempo los cambios estructurales para orientar el aparato productivo hacia el exterior y de llevar, más allá de sus límites económicos, el modelo de crecimiento fincado de manera exclusiva en el mercado interno.

La crisis de los ochenta fue, adicionalmente y sobre todo, una crisis del Estado (Bresser Pereira, 1999) que arrojó una lección importante para el futuro: la intervención del Estado destinada a dinamizar el crecimiento económico a través de manipulaciones en la demanda agregada había llegado a su fin, por los efectos desestabilizadores de los déficit públicos y, en general, de las políticas económicas expansivas. Ante el agotamiento de la sustitución de importaciones, la acción estatal orientada a este propósito se vuelve en portadora de crisis recurrentes.

Tesis 1: Un gasto público insuficientemente financiado por recursos fiscales debe ser desechado del inventario de instrumentos de política económica orientados a impulsar el nivel de actividad y el crecimiento, porque sus efectos sobre el nivel demanda agregada provocan crecimientos efimeros y destinados a generar desequilibrios que, al final, acaban por frenar el crecimiento.

La interpretación de la crisis del modelo de desarrollo y del modo de intervención estatal que ocurrió en los años ochenta es válida no sólo para México, sino para toda América Latina que, con la notable excepción de Chile, experimentó en la misma época un fenómeno similar:

"La gran crisis de América Latina en los años 80 fue la mayor de su historia. Fue ante todo una crisis del Estado, y no una crisis de mercado, como la gran depresión de los años 30: una crisis fiscal, una crisis del modo de intervención y una crisis de la forma burocrática de administrar el Estado. Fue asimismo, una crisis estructural del proceso de desarrollo anterior. No fue una mera consecuencia del proteccionismo, del estatismo y del populismo que prevalecían en América Latina, como pretende la interpretación neoliberal... En realidad, la gran crisis fue consecuencia de la propia dinámica del significativo desarrollo económico que hubo en América Latina entre los decenios de 1930 y de 1970. 
Este desarrollo ocurrió en el marco de una interpretación y de una estrategia nacional desarrollista, al amparo de una fuerte intervención del Estado” (Bresser Pereira, 1999: 105)

\subsection{El modelo secundario-exportador y la disfuncionalidad del patrón de intervención estatal}

La crisis de los años ochenta acarreó un mensaje adicional: el modelo de desarrollo debía transformarse hacia una dirección precisa: la exportación de manufacturas, como nuevo motor del crecimiento. La reorientación del aparato productivo hacia el exterior se visualizaba no como la mejor, sino como la única salida al atolladero en el que habían desembocado el agotamiento de la sustitución de importaciones, el abuso de las políticas fiscales y la expansión del Estado durante la década de los años setenta. ${ }^{3}$ Pero esta transformación demandaba una reforma en la actuación económica del Estado que, en los hechos, implicaba desmantelar una buena parte de los instrumentos en los que había reposado. Los elementos que dan cuenta de la incompatibilidad del nuevo modelo y el tipo de intervención económica vigente pueden enlistarse en forma reducida:

\subsubsection{Sistema de protección comercial, obstáculo a la exportación}

Cuando se quiere impulsar a la industria para que crezca a través del mercado interno, una política comercial proteccionista se vuelve un aspecto central, en la medida en que no solamente aísla la industria incipiente de la competencia foránea, sino — sobre todo- porque la protección efectiva introduce un sesgo antiexportador que favorece la rentabilidad del mercado interno con relación a la del mercado externo. Este fue uno de los principales instrumentos de la intervención estatal en el modelo de sustitución de importaciones. En cambio, cuando se aspira a que el crecimiento sea impulsado por la exportación, el sistema de protección representa un obstáculo que debe remontarse, en la medida en que impide que la oferta se oriente privilegiadamente $-\mathrm{y}$ no en forma excedentaria- hacia el exterior: los productores encontrarán siempre más rentable el mercado interno que la exportación.

\footnotetext{
${ }^{3}$ Una demostración matemática del carácter obligado de la transición hacia un modelo secundario exportador, se puede encontrar en Millán, 1998.
} 
Pero también el sistema de protección incide desfavorablemente sobre la demanda de bienes transables, en la medida en que, al estar libre de los mecanismos de competencia foránea, los agentes económicos carecen de los incentivos para aumentar la competitividad de sus productos y, por esta vía, de condiciones para penetrar los mercados internacionales.

Tesis 2: Una economía cerrada a la competencia externa inhibe la exportación. El sistema de protección comercial se vuelve incompatible con un esquema de inserción en la economía internacional, al que se ven obligados todos los países, si pretenden conservar su viabilidad en un contexto crecientemente globalizado. En el caso de México -así como en el de América Latinaese carácter obligatorio se acentúa en virtud de la alta dependencia que, estructuralmente, sigue manteniendo el crecimiento económico con relación a la disponibilidad de divisas, y por la inviabilidad que en el largo plazo muestra una politica de creciente endeudamiento externo.

\subsubsection{La intervención estatal obstaculiza la asignación eficiente} de recursos necesaria para penetrar los mercados externos

Uno de los instrumentos privilegiados por el intervencionismo estatal fue la regulación de precios y tarifas a través de controles de precios de factores y bienes, créditos blandos y subsidios a bienes de consumo popular e insumos de uso generalizado. Esta medida, que resultó crucial para impulsar la creación de una clase empresarial involucrada con el desarrollo industrial, generó distorsiones en el sistema de precios relativos que redundaron en una ineficiente asignación de los recursos. De esta forma, se impidió que operara una de las ventajas de toda economía de mercado: que tal sistema emitiera las señales correctas para que los recursos se canalizaran hacia sectores y ramas en las que podrían ser óptimamente utilizados. En un contexto de economía abierta y orientada hacia el exterior, este tipo de política obstaculiza el aprovechamiento de las ventajas comparativas en las que debe reposar una economía que necesita exportar y, al mismo tiempo, competir con los bienes de origen foráneo en el mercado interno.

La distorsión del sistema de precios no sólo se nutrió de las regulaciones y subsidios, sino también de un aparato paraestatal que, al regirse por una estructura de incentivos distinta a la del mercado, tendía a producir bienes y servicios cuyas cotizaciones no reflejaban los costos y beneficios sociales. En la medida en 
que esos bienes se distinguían por ser de uso generalizado, inyectaban sesgos en el sistema de precios que alteraban nocivamente la asignación eficiente de los recursos.

Tesis 3: La intervención del Estado a través de regulaciones y de la producción de empresas paraestatales tiende a distorsionar el sistema de precios relativos y, en consecuencia, a restar la competitividad global de la economía nacional. En este sentido, las regulaciones y la producción paraestatal deben operar cuando sean estrictamente necesarias, tratando de minimizar sus efectos sobre el sistema de precios; asimismo, los subsidios deben abandonar su carácter generalizado y canalizarse focalizadamente a sectores sociales previamente determinados, y nunca a productores, con excepción de aquellos que no tenga al mercado como destino fundamental.

\subsubsection{Inflación, competitividad y tipo de cambio}

La inflación es un proceso incompatible con el modelo de crecimiento hacia fuera. Cuando registra tasas superiores a la de los principales socios comerciales, el encarecimiento permanente revierte los avances en la competitividad y en la productividad. Asimismo, la oferta tiende a orientarse al mercado interno. La consecuencia no puede ser otra que la reducción del volumen de exportaciones y el desplazamiento de la producción doméstica por las importaciones.

Por tal razón, la política económica de corto plazo debe asegurar la estabilidad macroeconómica no sólo en el frente externo, sino en el interno. Tal exigencia desencadena un conjunto de modificaciones que, en los hechos, despoja al Estado de dos de sus instrumentos "macro" de injerencia en la esfera económica: el manejo discrecional de la oferta monetaria y del tipo de cambio.

Estos instrumentos eran parte nodal del intervencionismo estatal asociado a una economía cerrada: la política monetaria posibilitaba el financiamiento inflacionario de los desequilibrios fiscales, la canalización selectiva de crédito y su suministro a tasas de interés inferiores a la del mercado. El manejo del tipo de cambio propiciaba frecuentemente la sobrevaluación del peso que, en el fondo, representaba una forma particular de subsidio a las empresas industriales en la importación de bienes de capital e intermedios. En la medida en que la política industrial - y de desarrollo- fue diseñada bajo un esquema proteccionista, en el 
que los requerimientos de divisas los cumplían fuentes extraindustriales —agricultura, turismo, deuda, petróleo-, la política de tipos de cambio fijos y moneda sobrevaluada pudo sostenerse durante largos periodos, sin importar el menoscabo sobre la actividad exportadora. Los problemas afloraron cuando esas fuentes se agotaron, pero el esquema se volvió insostenible cuando las circunstancias obligaron a transformar el patrón de desarrollo.

El arribo de un modelo secundario-exportador se vuelve incompatible con este manejo de las políticas cambiaria y monetaria, y por este conducto, con uno de los rasgos centrales de la antigua intervención estatal. Bajo el nuevo esquema, el combate a la inflación demanda la autonomía del banco central y el establecimiento de un régimen de tipo de cambio flexible; ambas exigencias conducen a un nuevo tipo de intervención estatal que sea compatible con la nueva dinámica de la acumulación de capital.

Tesis 4. En una economía abierta, la exigencia por mejorar la competitividad implica un combate permanente a la inflación hasta que registre tasas similares a las internacionales, y un tipo de cambio real constante. En el terreno institucional, estas exigencias demandan autonomía del Banco Central y régimen de tipo de cambio flexible.

\subsection{El debilitamiento del sistema político y los límites del intervencionismo estatal}

La necesidad de reconformar al Estado que se había desmoronado tras la caída del Porfiriato, condujo a un sistema político de rasgos acentuadamente autoritarios. Entre éstos destacaban el tutelaje estatal sobre la sociedad civil y la exclusión de la democracia como fuente de legitimidad. Ambos, a su vez, se habían fincado en dos pilares centrales de la mecánica política mexicana: un esquema corporativo, que fue impuesto como conducto único para la expresión y representación de los intereses; y un sistema presidencialista que concentraba el poder en el Ejecutivo y le confería facultades cuasiabsolutas de árbitro en los conflictos y en los ascensos políticos. Por su parte, el nacionalismo se constituyó en una pieza clave para garantizar la unidad nacional y para lubricar la mecánica de un sistema siempre desafiado por una sociedad en constante mutación. 


\subsubsection{Representación corporativa}

Bajo esta modalidad, la intervención del Estado en la economía no solamente era funcional al modelo de desarrollo, sino una de las piezas insoslayables que nutrían el funcionamiento del sistema político. En la medida en que la democracia no constituía una fuente privilegiada de legitimidad, ésta tendió a reposar en bases más directamente relacionadas con la promoción de intereses de los grupos y clases sociales que integraban el pacto corporativo como el crecimiento económico, el nacionalismo y una gama muy amplia de instancias redistributivas que pretendían contrarrestar los efectos de la dinámica industrializadora sobre los estratos populares. A cambio del apoyo político, se desplegó una política de Estado — que no de gobierno- de concesiones intermitentes capaz de mantener un equilibrio político - no económico, ni social- entre los factores de la producción:

i) El Estado mexicano, a diferencia del patrón clásico europeo occidental, aparece como creador y criador del empresariado nacional. Este es el encargado directo de desplegar una de las fuentes alternativas de legitimidad: el crecimiento económico. Pero para que tal propósito se cumpliera, el Estado debió ejercer la función de crear y desarrollar un empresariado - sobre todo industrial- hasta entonces prácticamente inexistente en el escenario nacional. Por tal razón, desplegó sus baterías hacia la constitución de un eficaz sistema que protegía a las empresas de la competencia externa y que suministraba generosas exenciones y facilidades fiscales; que otorgaba créditos blandos y garantizados, y subsidios en los insumos de uso generalizado; que aminoraba los riesgos privados de quiebra, al posibilitar la transformación en empresas públicas de unidades fabriles en dificultades; que podía contener las demandas laborales, en virtud de la administración corporativa del movimiento obrero; que dirigía una buena parte del gasto público a la infraestructura; y que posibilitaba el suministro barato de materias primas y alimentos, al subordinar la actividad agropecuaria a las necesidades y dinámica de la industria nacional. Por tal razón, hasta la década de los setenta, con la constitución del Consejo Coordinador Empresarial, los empresarios no dudaron en respaldar las acciones gubernamentales (Hernández, 1988). Un despliegue de esta índole sólo podía estar avalado por una fuerte intervención estatal en la economía. 
ii) El consenso del movimiento obrero estaba fundado en un sistema de protección al trabajo y la inclusión de los líderes corporativos en las esferas políticas mexicanas. La alianza que el Estado mexicano estableció con el movimiento obrero se fincó en el mismo esquema de apoyos y concesiones. En este caso, la intervención estatal se manifiesta en un sistema que protege al trabajador, aunque esta protección se despliega bajo una mecánica que subordina los intereses obreros a los del Estado y, frecuentemente, a los de la élite política. A cambio del apoyo corporativo, los obreros reciben seguridad social, salarios mínimos, acceso a la vivienda, control de precios y una legislación laboral que, por lo menos en términos formales, pretende equilibrar las relaciones entre capital y trabajo.

Por si fuera poco, el pacto corporativo está diseñado para que los líderes obreros participen en la política a través de puestos de elección popular y en la toma de decisiones económicas que afectan al factor trabajo o que necesitan el respaldo obrero para aspirar al éxito: es la forma en la que ese pacto administra la representación de intereses de los trabajadores.

En esta lógica, la fuerza política de los líderes sindicales se encuentra - por lo menos así era en sus mejores momentosentre dos fuegos: el respaldo que recibe del gobierno, por un lado, y la capacidad de control sobre el movimiento. El primero depende del segundo; y éste, del flujo de concesiones que puede arrancarle al Estado. Para que el aparato pueda seguir funcionando, es preciso una activa intervención estatal.

iii) Los campesinos son incorporados al Estado a través del reparto de tierras —sobre todo del ejido-, de una politica administrada de precios e ingresos y de la inclusión de sus representantes al juego político. La política de reparto agrario constituyó uno de los factores más influyentes de la conformación del Estado mexicano, en la medida en que el grueso de las dotaciones se ejecutó en una época en la que la mayoría de la población era de origen rural. Los campesinos vieron reflejados sus intereses más inmediatos en el Estado. Su origen revolucionario le impulso a librar la batalla contra la oligarquía terrateniente porfiriana; pero sobre todo porque la capacidad de usufructo de la tierra quedó, hasta la reforma del Artículo 27 constitucional, ligada al Estado, en virtud de que una buena parte permaneció como propiedad de la nación. Por tal razón, el mantenimiento de esta fuente de 
consenso requirió de la prolongación de la política de reparto más allá de los límites físicamente permisibles.

Complementó el reparto una política agraria, que garantizó precios mínimos a los cultivos más sensibles para el ingreso campesino y que activó una impresionante infraestructura para la comercialización; que facilitó la adquisición de insumos y promovió la asistencia técnica; y que desarrolló un aparato crediticio muy favorable para las actividades primarias. En un contexto de riesgo mínimo -implícito el carácter inembargable del ejido- tal política inhibió las capacidades empresariales de este sector social y prolongó el tutelaje estatal más allá de lo que hubiera indicado un principio sensato de subsidiaridad.

En este juego, la mecánica corporativa fue insustituible: al igual que en los casos obrero y empresarial, la organización campesina a cargo del Estado fue el expediente más socorrido de representación de intereses. Los esquemas cupulares, asociados a esta práctica, complementaron el cuadro que se necesitaba para instrumentar el control estatal. Para ejercerlo, los dirigentes campesinos - como los obreros y empresariales- debían mantener vivo el flujo de concesiones derivados de la intervención estatal en el campo. Cuando las circunstancias o las necesidades derivadas de la preservación de los equilibrios políticos no lo permitían, el control era frecuentemente garantizado por la represión. En última instancia, eso es el Estado: consenso y coerción.

iv) El Estado asoció la representación de los estratos medios con la burocracia, en virtud de que sus miembros aparecian como los grupos directamente corporativizables; al resto los cooptó por otros medios, más cercanos a la movilidad social. En ambas líneas, la intervención del Estado representaba un baluarte indispensable. La expansión y preservación de un abultado aparato estatal- administrativo suministraba a los estratos burocráticos la seguridad laboral necesaria para garantizar su adhesión al Estado. La educación pública, por otro lado, proporcionaba oportunidades de ascenso en la estructura social por vías meritocráticas, que son propias de estos estratos, al tiempo que demandaba una fuerte presencia del Estado en la formación de la conciencia nacional, posibilitada por el control corporativo de los maestros. 


\subsubsection{Presidencialismo, circulación de las élites e intervención estatal}

Concebido bajo el modelo norteamericano, el sistema político adoptó el régimen presidencial; sin embargo, este régimen derivó en un presidencialismo que alteró el equilibrio de poderes a favor del Ejecutivo, en virtud de que este esquema ofreció la única solución para encarar las tendencias centrífugas que desde el siglo XIX se instalaron en México y que, ante la ausencia de un marco institucional sólido, afloraban cada vez que se debilitaba el poder central.

Tras el movimiento de 1910, la salida que la burocracia político-militar diseñó para resolver este problema fue la conformación de un cuadro de instituciones en torno a la Presidencia no al presidente- de la República. El Ejecutivo en turno asumía una triple jefatura: la del Estado, la del gobierno y la del partido dominante. Bajo este artificio, se combinaron facultades constitucionales y metaconstitucionales (Córdova, 1974) que concentraron en la institución presidencial un poder inédito — quizásdesde los tlatoanis mexicas. Ambas le permitieron ejercer funciones de arbitraje entre los factores de la producción (Artículo 123 constitucional), en las relaciones de propiedad (Artículo 27 constitucional) y con la Iglesia (Artículo 130 constitucional), así como en las disputas por puestos políticos (jefatura de partido).

El ejercicio de estas facultades de arbitraje demandaba la activación de un flujo de acciones que abrían la puerta a la presencia estatal en la economía: las nacionalizaciones frecuentemente exhibían la acción arbitral entre actores en conflicto (la petrolera). Pero quizás la vinculación más estrecha entre el presidencialismo e intervencionismo estatal haya sido labrada por la necesidad de mantener la estabilidad política. Y en ella la circulación de las élites gobernantes jugaba un papel significativo: la renovación presidencial - a diferencia del Porfiriato- posibilitaba una inclusión más acelerada de nuevos actores a la arena oficial y el desplazamiento de figuras políticas destacadas y, eventualmente, con capacidad política propia. Su subordinación a los designios presidenciales demandaba la garantía de un futuro sin trastornos económicos, que el mismo sistema debía suministrar.

La intervención estatal facilitó que el sistema político cumpliera con el encargo: las regulaciones propiciaron la corrupción y, por esta vía, el enriquecimiento de políticos, prominentes y menores, facilitando que la circulación de las elites fluyera sin 
desafíos significativos al mandato presidencial. En igual sentido operaron la política de concesiones de actividades productivas en beneficio de quienes estaban destinados a desaparecer de la arena política; la de compras estatales de bienes y servicios, así como otras formas de connivencia entre el Ejecutivo y miembros retirados del sistema.

\subsubsection{Nacionalismo e intervención estatal}

El nacionalismo mexicano tiene orígenes históricos que pueden ser rastreados en la refuncionalización operada por los criollos del pasado prehispánico y el guadalupanismo para configurar una ideología que trabajara en favor de la independencia de Nueva España (Brading, 1980). En la ideología de la Revolución, asumió un significado, si no exclusivo, sí predominantemente económico; pero también defensivo frente a la hegemonía de las potencias internacionales, señaladamente la de los Estados Unidos. La preservación de los recursos naturales y el abasto de insumos estratégicos en manos del Estado pretendía ser una respuesta al rol que en el Porfiriato había jugado el capital de enclave: las compañías extranjeras no solamente habían logrado entronizarse como el pivote del funcionamiento del modelo primario-exportador, sino también constituirse frecuentemente en factores de poder factual, contra los cuales el Estado exhibía una debilidad estructural (Benítez, 1980).

En la memoria aún prevalecía el trato discriminatorio hacia los trabajadores mexicanos (Car, 1973), la participación de las guardias de Arizona en la represión de la huelga de Cananea, la embestida norteamericana contra la aplicación retroactiva del Artículo 27 constitucional y la desobediencia de las empresas petroleras ante el laudo a favor de sus trabajadores. Tales hechos habían configurado una predisposición adicional en el pueblo mexicano a asumir el nacionalismo como defensa contra agentes que, por definición, obedecían a intereses ajenos a la nación. En un contexto de profunda desigualdad social, la burocracia político-militar que emergió de la Revolución activó una idea de nación que trabajó a favor de la construcción de un "Nosotros" (para utilizar la figura de O’Donell, 1980) que, al trascender estas disparidades, abonaba un ingrediente indispensable para la estabilidad política: el destierro de revueltas populares contra el orden social. 
En este sentido, el nacionalismo defensivo inundó el discurso oficial y la política exterior, pero también la esfera económica: el monopolio o control estatal de segmentos claves para los proceso productivos era, antes que cualquier otra cosa, una actitud preventiva que pretendía evitar el paso de la propiedad privada, en manos de nacionales, a la propiedad extranjera. Tal política derivó en una injerencia estatal en amplios tramos del proceso productivo nacional.

\subsubsection{Crisis del sistema politico, crisis del intervencionismo estatal}

La quiebra del modelo de crecimiento coincidió con la extenuación del sistema político. Pero más allá de las relaciones causales que puedan existir entre ambos, el sistema político mostró signos crecientes de incompatibilidad con la racionalidad propia de una economía abierta; la crisis que experimentó lo relevó de las responsabilidades que lo empujaban a llevar la intervención estatal más allá de las prescripciones en boga y de las que imponían las condiciones del desarrollo:

i) El sistema corporativo se deteriora porque la crisis económica conduce a la incapacidad del Estado de seguir administrando arbitrariamente, $y$ sin detrimento de la competitividad, los ingresos $y$ prestaciones que beneficiaban a las clases populares. La necesidad de apuntalar el crecimiento económico a través de las exportaciones colocó a la competitividad en el centro de la estrategia económica, seguida a partir de 1982. Una política administrada de salarios e ingresos agrícolas que ubique las remuneraciones de los factores productivos por encima de las productividades se vuelve, entonces, incompatible con esa estrategia: el impacto en los costos y en la inflación no tardaría en contrarrestar los eventuales logros en el rubro de la competitividad y el empleo.

De esta forma, la instauración del modelo de economía abierta destraba en su contra el dilema de los apóstoles del corporativismo: en la medida en que la nueva dinámica económica se impone, la preservación de la competitividad imposibilita que los líderes corporativos puedan arrancar del Estado nuevas prebendas e, incluso, consolidar las obtenidas en los mejores tiempos del llamado populismo. Su capacidad de representación es minada por la interrupción de ese flujo de concesiones que hizo posible su alianza histórica con el Estado, en el mismo grado en 
que se muestran impotentes para detener las demandas populares que se procesan por canales alternos al control estatal. La consecuencia es el quebranto del otro polo de la relación entre Estado y la dirigencia corporativa: su utilidad y funcionalidad como sustento consensual del Estado.

ii) El propio desarrollo económico propició la diversificación de la estructura social, que se tradujo en la emergencia de actores no corporativizables, quienes cobraron creciente importancia en los procesos políticos y para quienes la democracia representó un canal más idóneo de representación de sus intereses. Tales actores, especialmente los estratos medios, contribuyeron a cimentar una cultura meritocrática que independizó su destino individual tanto del Estado como de las formas patrimoniales de movilidad social. Beneficiarias más inmediatas del desarrollo económico, las clases medias habían crecido al amparo del Estado y, especialmente, de su política educativa e industrializadora, que configuraron espacios económicos privados y alternativos para su desenvolvimiento al margen de la acción Estatal. Para ellos, el complejo corporativo no sólo resultaba ajeno, sino incapaz de arroparlos bajo el manto de la tutela estatal.

En la medida en que se fueron constituyendo en el núcleo dinamizador de la opinión pública, su apoyo fue trascendental para la configuración de nuevas bases consensuales del Estado: éste propendió a ceder crecientemente a sus exigencias, especialmente en la disputa por los recursos públicos canalizados a revitalizar la mecánica corporativa, pues éstos reposaban en los impuestos de los pocos contribuyentes, entre los cuales se encontraban los estratos medios. Esto contribuyó definitivamente al menoscabo de este esquema corporativo de representación. En su lugar, impulsaron el avance democrático, afín a su visión meritocrática, en un contexto en el que las bases tradicionales de legitimación, como el crecimiento y la política de bienestar, se extenuaban y cedían el paso a los procesos electorales.

El peso medular de los estratos medios en la configuración del consenso y su visión meritocrática afianzaron en la opinión pública la idea de que el intervencionismo estatal había llegado a sus límites y que, ahora, debía emprender el camino de regreso.

iii) El presidencialismo ingresó en un proceso de deterioro que ha puesto en crisis el "estilo personal del gobernar" (Cosío, 1977). A este proceso han contribuido los descalabros de la política eco- 
nómica; las escisiones en el partido oficial, que cuestionaron al presidente la facultad metaconstitucional de elegir a su sucesor; el resurgimiento de poderes locales que cuestionan el poder central; y el nuevo papel protagónico de un legislativo que, en su Cámara Baja, logró la mayoría opositora.

Tesis 5. El sistema corporativo es incompatible con una economía abierta, porque aquél descansa en un manejo discrecional de variables claves para la competitividad.

Tesis 6. Los estratos medios se han vuelto el núcleo a través del cual se configura y dinamiza la opinión pública, y por ello, una de las bases centrales del consenso en torno a la gestión estatal. En la medida en que esos estratos guían su acción por valores de indole meritocrática, la legitimidad de la intervención estatal se encuentra fuertemente acotada por una visión similar. Solamente admite excepciones cuando por la disparidad social está anclada en la desigualdad de oportunidades.

\section{La inviabilidad política del modelo neoliberal}

La crisis de 1982 puso de manifiesto que el modelo de desarrollo y del patrón de intervención estatal habían tocado fin. En el ámbito político, la circulación de las élites acusó un giro hacia el ascenso de una clase tecnocrática que, a diferencia del político asociado al esquema corporativo, había recorrido un itinerario que, ni para ejercer la demagogia, se había cruzado con el sentir el pueblo mexicano. Estos grupos tecnocráticos utilizaron el esquema neoliberal como un parteaguas histórico que pretendía refundar la nación bajo un paradigma modernizador.

La política neoliberal acertó en la empresa de introducir cambios estructurales en la orientación del aparato productivo hacia el exterior, en el saneamiento de las finanzas públicas, el redimensionamiento económico del Estado, la desregulación de numerosas actividades económicas y, en última instancia, en la refuncionalización de la iniciativa individual como protagonista del proceso económico y social. Con tales vuelcos, el mercado se erigió como el mecanismo privilegiado en la asignación de los recursos. La esperanza de que por esa vía la modernización arrojaría resultados contundentes en el bienestar, se fincó en que, bajo las mismas reglas institucionales, todos los agentes responderían homogéneamente a los incentivos implícitos en la lógica del mercado, con el consecuente beneficio para la nación. La identificación entre interés individual y social, propia de toda visión 
liberal, resurgía con bríos y fundamentos renovados que, para desgracia del pueblo mexicano, la historia reciente acabaría por desmentir.

Después de más de quince años de obstinada aplicación, el neoliberalismo ha demostrado su insuficiencia para resolver problemas estructurales que afectan el desempeño económico nacional; pero también ha exhibido una proclividad, también estructural, a ahondar las diferencias entre los mexicanos, a debilitar la cohesión social y a procrear un Estado que actúa a favor de oligarquías financieras y empresariales.

\subsection{El neoliberalismo y el desempeño económico}

La capacidad de la política neoliberal para hacer de la exportación manufacturera el componente más dinámico del crecimiento económico, ha sido contundente. Ha respondido atinadamente al agotamiento de las fuerzas endógenas que acompañó a la extenuación de la sustitución de importaciones y a la necesidad de insertarse en los mercados internacionales. Sin embargo, al combinarse con una estructura conformada por particularidades históricas y por condiciones propias del subdesarrollo, la política neoliberal ha instaurado un funcionamiento que dista mucho de propiciar el desempeño económico que demanda la nación. Éste puede caracterizarse por los siguientes elementos inherentes a la mecánica neoliberal desplegada en un contexto, como el mexicano, de heterogeneidad estructural, condición que pasan por alto sus apologistas:

i) El complejo secundario-exportador tiende a operar como un enclave sin vinculaciones que permitan arrastrar en su dinamismo al resto de la economía. En este sentido, ahonda la heterogeneidad estructural, propia de una economía subdesarrollada. El éxito de la política neoliberal para reorientar el aparato productivo es incuestionable: mientras en 1982, el petróleo contribuía con $73 \%$ de la exportación nacional, hoy más de $80 \%$ está conformado por manufacturas. Sin embargo, la exportación se concentra en pocos productos, pocas empresas y pocos mercados, mientras la mayoría de las unidades productivas permanecen al margen de esta actividad orientada hacia el exterior.

Para países que han emprendido estrategias exportadoras, esta situación es normal, porque sólo las empresas más aptas son capaces de incursionar en mercados internacionales cada vez más 
competidos: los beneficios que recibe la economía derivan de los efectos multiplicadores que esas unidades activan sobre el resto de las actividades productivas. En el caso de México no es así: los productos que dominan la exportación se caracterizan por mantener escasas relaciones sectoriales con el conjunto de las actividades económicas. Estos productos consisten, fundamentalmente, en bienes de consumo duradero (bienes automotrices, electrodomésticos, etcétera), cuya elaboración demanda pocos insumos nacionales y exhibe una alta propensión a abastecerse de bienes intermedios importados. En este sentido, la exportación muestra escasa capacidad de arrastre —efectos hacia atrássobre la producción nacional y la consecuente ampliación del mercado interno.

La débil vinculación que sostiene la exportación con el resto de la economía ha tendido a agravarse con el rompimiento de las cadenas productivas que ha acarreado la apertura externa: los afanes competitivos de las empresas exportadoras han propiciado el desplazamiento de proveedores nacionales por las importaciones. En este proceso están involucrados problemas de insuficiencia competitiva de esos proveedores, pero también estrategias corporativas de empresas transnacionales, centradas en el comercio intrafirma: las sucursales que operan en México tienden a abastecerse de sus matrices, por las ventajas que esta mecánica entraña en términos de precios de transferencia e integración vertical.

Además, el carácter de enclave que reviste al complejo exportador mexicano se manifiesta en que tampoco produce los efectos "hacia delante" que la producción de bienes de consumo duradero generaban en el modelo de desarrollo anterior. En la segunda fase del proceso de sustitución de importaciones, la producción de durables desempeñó el papel de sector líder de la acumulación de capital (Pinto, 1973), a pesar de la desvinculación intersectorial y en virtud de su capacidad para generar "efectos hacia delante" (Tavares, 1981; Lustig, 1981), pues su consumo debía ser complementado por un programa de obras públicas (carreteras, electricidad, etcétera) y por servicios asociados que incidían amplia y favorablemente sobre el empleo y, por este conducto, por sobre el mercado interno. Bajo el nuevo modelo, esos efectos se exportan.

El aislamiento intersectorial de la actividad exportadora es el responsable, en última instancia, de una paradoja de una política neoliberal aplicada en un contexto estructural heterogéneo: 
el desencuentro permanente entre el desempeño macroeconómico y la microeconomía. Pero también es un ejemplo elocuente de las distorsiones que propicia esa política neoliberal cuando se aplica abstrayéndose de una realidad histórica: la dinámica propia del desarrollo ubicó a la producción de bienes durables como el sector-eje de la acumulación de capital en la última fase del proceso sustitutivo de importaciones; cuando el modelo se transforma en otro fincado en la exportación manufacturera, esa producción vuelve a asumir el liderazgo, pero en un escenario en el que el mercado externo - y no el interno- representan la fuerza motriz del crecimiento. En ausencia de una política industrial -que supone la intervención estatal- y con el destino de la industria sujeto únicamente a los devaneos del mercado, el modelo secundario-exportador puede acumular éxitos en los mercados internacionales, pero nunca traducirlos en un mayor bienestar social. Antes bien: propende a abrir la brecha entre sectores modernos y sectores rezagados, que son los que están asociados al mercado interno. El problema es que nosotros somos el mercado interno.

Tesis 7. La orientación del aparato productivo hacia el exterior es una estrategia que debe mantenerse, en virtud del agotamiento de las fuerzas endógenas del crecimiento y de la necesidad de incrustarse en los mercados internacionales. No obstante, tal orientación debe acompañarse por una decidida politica industrial dirigida a impulsar la competitividad de los proveedores de insumos nacionales, la articulación de las cadenas productivas y la ampliación de la base exportadora a bienes con mayor contenido nacional.

ii) El desarrollo exportador se realiza a costa, y no a favor, del mercado interno al cual están asociados las empresas de menor dimensión, que son las que más absorben empleo. La apertura externa jugó un papel clave en la reorientación de la actividad productiva hacia el exterior, tanto por sus efectos en la competitividad como por la reversión del sesgo antiexportador, que favorecía la rentabilidad relativa del mercado interno. Sin embargo, la apertura instaló dos efectos contrarios sobre el crecimiento: el efecto exportador impulsa la actividad económica, mientras las importaciones tienden a desplazar la producción doméstica destinada a abastecer el mercado interno. Las estimaciones sobre el saldo neto de ambas fuerzas calculan que los efectos negativos superan a los positivos (Millán, 1997), disminuyendo la tasa po- 
tencial del crecimiento. Pero más importante es que la apertura económica fue desplegada sin un programa que combinara la desgravación arancelaria con impulsos a la competitividad de actividades orientas privilegiadamente al mercado interno; en este sentido, se produjo un conflicto permanente entre el desarrollo del mercado interno y la promoción de exportaciones.

A este hecho se ha aunado la evolución dispareja entre productividad laboral y salarios reales: mientras el modelo secundario-exportador ha propiciado un empuje impresionante en la eficiencia laboral manufacturera, las remuneraciones reales de esta actividad han declinado o crecido a un ritmo inferior al de la productividad. La consecuencia de este fenómeno es un relativo estancamiento del mercado interno, que amenaza con romper los círculos virtuosos entre productividad, mercado interno y progreso técnico (Fajnzylber, 1980). De esta forma, se refuerza la distancia que separa al bienestar del desempeño económico y la brecha entre grandes empresas exportadoras y entidades productivas de menor dimensión, generalmente asociadas al mercado interno.

La causa de este comportamiento también reside en la combinación de la política neoliberal y la estructura económica heterogénea e incompleta: al enfrentar una apertura externa abrupta y acelerada, las empresas se vieron en la necesidad de endeudarse para reconvertir sus procesos productivos, en un contexto en que eran desplazadas por las importaciones en el mercado interno; sin embargo, la liberación del sistema financiero sin una reforma profunda que incidiera favorablemente en las tasas de interés, impuso a esas unidades productivas una carga financiera que amenazaba con eliminarlas del nuevo esquema competitivo. La respuesta consistió en utilizar al salario como variable de ajuste: el diferencial entre productividad laboral y salario operó como mecanismo de financiamiento de esa carga financiera y de competitividad espuria. Los datos muestran que mientras la productividad laboral aumenta sostenida y significativamente, los salarios reales crecen a un ritmo inferior y, frecuentemente, incluso llegan a disminuir.

Tesis 8. El modelo secundario-exportador impulsa la eficiencia económica, pero para que ésta se refleje en bienestar social es imprescindible operar una politica laboral en la que los salarios reales evolucionen con la productividad; pero esto no es posible sin una reforma del sistema financiero que apuntale las tasas de 
interés hacia los niveles internacionales y sin la conservación de un marco macroeconómico estable que aminore el riesgo-país.

iii) La dinámica económica tiende a registrar tasas de crecimiento insuficientes para absorber a los nuevos contingentes de la fuerza laboral, que al ser rebasadas propician desequilibrios que amenazan con restituir los mecanismos que han conducido a las crisis recurrentes. El efecto más sensible de la política neoliberal ha sido su incapacidad para mantener tasas de crecimiento altas y suficientes para absorber a los nuevos contingentes que anualmente se incorporan a la fuerza laboral: la restricción de ahorro y la restricción externa ubican entre 3 y $3.5 \%$ la tasa de crecimiento compatible con la conservación de los equilibrios macroeconómicos o con desbalances moderados en el frente externo y en las finanzas públicas; en cambio, las exigencias derivadas de las necesidades de empleo demandan un ritmo de expansión económica de, al menos, $5 \%$.

Con el neoliberalismo y la globalización, el ahorro macroeconómico ha entrado en una verdadera encrucijada: por un lado, las necesidades de mantener un marco de estabilidad para evitar presiones inflacionarias que reviertan la competitividad, origina una política tendiente a atemperar el crecimiento de la demanda agregada y el ingreso, que es uno de los determinantes fundamentales del ahorro; en este sentido, se reducen las posibilidades de financiar el crecimiento con una política deliberada de expansión acelerada del ingreso. Por el otro, se apuesta a tasas de interés reales atractivas, que si bien podrían estimular el ahorro, tienden a deprimir la inversión y el nivel de actividad; al traducirse en un nivel o en un crecimiento del ingreso inferior, frenan los avances en el ahorro.

En adición, la apertura comercial ha introducido cambios que alteran las tasas de crecimiento económico compatible con el equilibrio en la cuenta corriente de la balanza de pagos: aunque el crecimiento de las exportaciones ha impulsado el ritmo de expansión de la economía, el salto estructural que ha propiciado la apertura externa en la elasticidad ingreso de las importaciones, lo ha superado y, en consecuencia, ha disminuido esta tasa de crecimiento equilibrado.

El mensaje implícito en esta dinámica es la instalación de una nueva contradicción entre empleo y estabilidad macroeconómica, que contraviene la doctrina neoliberal: para que el crecimiento económico pueda operar como un instrumento capaz de 
evitar la ampliación del desempleo, la dinámica económica debe violentar las restricciones que imponen la insuficiencia de ahorro y el balance externo; pero al hacerlo, desencadena efectos desestabilizadores que reproducen la mecánica entre desequilibrios externos, devaluaciones y políticas restrictivas, que han caracterizado las crisis recurrentes.

El dilema entre estabilidad y crecimiento debe y puede ser resuelto por acciones que se alejan de las prescripciones neoliberales y que demanda una decidida intervención estatal. Estas pueden derivar de recomendaciones alternativas que sugieren el impulso al ahorro a través de disposiciones fiscales que aumenten la recaudación proveniente del consumo (IVA) y la introducción de esquemas de ahorro forzoso: las primeras propician un mayor ahorro público, en la medida en que aumentan los ingresos tributarios; pero también generan un mayor ahorro privado, al inhibir el consumo. Un segundo frente es sugerido por las llamadas "nuevas teorías del crecimiento", que enfatizan el papel de la formación del capital humano y de los rendimientos crecientes en las actividades productivas como fuentes genuinas de crecimiento sostenido.

Tesis 9. La politica económica debe tener como uno de sus objetivos centrales la consecución de tasas de crecimiento suficientes para abatir el desempleo; ello implica una estrategia destinada a relajar las restricciones que imponen la insuficiencia de ahorro y el equilibrio externo, pero también, la exploración de fuentes alternativas de crecimiento como la formación del capital humano y la difusión del conocimiento tecnológico, cuyas externalidades aumentan la productividad de los factores productivos.

iv) La economía se ha vuelto más vulnerable frente a choques externos y no ha podido remontar la asociación entre crecimiento $y$ desequilibrio en la balanza de pagos; antes bien, la correlación entre ambos se ha acentuado. La insuficiencia de ahorro interno se ha traducido en déficits permanentes en la cuenta corriente de la balanza de pagos, que han acarreado la necesidad de financiamiento foráneo, especialmente bajo la forma de inversión extranjera, tanto directa como la destinada a la adquisición de activos financieros. A pesar de que la apertura comercial -especialmente el TLCAN- propició un salto cuantitativo en los montos de la IED (de 3 a 10 mil millones de dólares), éstos han mostrado una tendencia a estancarse en esos niveles y, por tanto, a ser insuficientes para financiar el desequilibrio corriente en las 
cuentas externas. En virtud de que la política neoliberal de largo plazo no ha sido capaz de remontar la correlación entre crecimiento y déficit externo, el financiamiento tiende a reposar en la inversión en cartera, generalmente de corto plazo, que se caracteriza por su alta volatilidad. La consecuencia es que la economía mexicana se ha vuelto muy vulnerable a choques externos que animan a esos capitales especulativos a trasladarse hacia otros mercados de dinero y de capital.

Tesis 10. La reducción de la vulnerabilidad externa debe pasar por disminuir la inestabilidad de los ingresos públicos, que es una condición necesaria pero insuficiente. Para complementarla, se ha recomendado la introducción de impuestos a los capitales volátiles; sin embargo, esta medida puede resultar contraproducente si no es acompañada por un acuerdo internacional que comprometa a todas las economías a actuar en la misma dirección. La imposición unilateral pueda derivar en la pérdida de atractivo de los mercados nacionales, a favor de otras economías emergentes. La acción multilateral, en cambio, anula este riesgo y representa un ejemplo elocuente de que los problemas globales requieren soluciones globales.

v) La agricultura tiende a rezagarse frente al desarrollo nacional. La estrategia del nuevo modelo de desarrollo centra su atención en la exportación de manufactura; es, en este sentido, un proyecto reindustrializador y no desindustrializador, como llegó a pensarse en los primeros años en los que empezó a operar en América Latina. En ella, la exportación agropecuaria tiene un carácter marginal, tanto por el exiguo peso relativo del sector en las ventas externas como por su debilidad estructural para competir en los mercados internacionales.

Sin embargo, la apertura externa también se ha extendido hacia las actividades primarias, provocando un horizonte desolador: en un contexto internacional en el que la sobreproducción agrícola adquiere rasgos estructurales y los precios exhiben una tendencia declinante, las economías más desarrolladas han desplegado una política de subsidios, que combinados con las revoluciones en los campos de la biotecnología y de los llamados nuevos materiales, vulneran drásticamente la condición de los productores nacionales para encarar los retos de la competencia externa.

Para preservar la política comercial, el neoliberalismo mexicano ha respondido, en esencia, mediante dos vías: el suministro 
de subsidios y la introducción de reformas constitucionales destinadas a alterar la racionalidad campesina frente a su producción y a la recapitalización del campo. En el mejor de los casos, los subsidios agrícolas (Procampo) podrían compensar las subvenciones que reciben sus competidores internacionales, pero no las diferencias abismales en la productividad; las cuales están determinadas no solamente por usos más eficientes de los recursos, sino por la naturaleza de éstos: la calidad de la tierra de grandes extensiones campesinas es sustancialmente inferior a la de sus competidores; y carece de agua y otros atributos que sólo la naturaleza puede suministrar.

El credo neoliberal tiene una prescripción para estos casos, que de nuevo tropieza con las características históricas e idiosincráticas de la cultura nacional: la conversión de cultivos o el abandono de la tierra. En cambio, la lógica con la que el campesino enfrenta la tierra y la producción entrevera la seguridad que deriva de la tradición con otros aspectos relacionados con el cálculo económico; es una mezcla de lo que Weber llamaba racionalidad con respecto a fines, en la que se cimientan el mercado y la modernidad, con una racionalidad con respecto a valores. Entre éstos se encuentra su actitud hacia la producción, que antepone el carácter consuntivo al lucrativo; la seguridad y la supervivencia, al riesgo y sus beneficios; y la visión de la tierra como vínculo de solidaridad entre generaciones, a aquélla que la considera un simple un factor productivo.

Inspirados en otras vertientes que reconocen la influencia de las instituciones en el desempeño económico (Norton, 1995; Burki y Perry, 1998), los neoliberales impulsaron la reforma al Artículo 27 constitucional con la finalidad de reducir a una las dos racionalidades del campesino: la del mercado. Al ser posible que las tierras ejidales pasaran a manos privadas, pretendía introducir el riesgo - y por tanto, el beneficio- como nuevo motivador del comportamiento económico del productor agrícola. Así se propiciaba la transformación del campesino en un empresario agropecuario, pretendiendo uniformar a ese segmento tan importante de la población. Se esperaba que este cambio de racionalidad llevara a los campesinos a introducir una utilización más eficiente de los recursos, al aumento de la productividad y, finalmente, a situarlo en condiciones de enfrentar exitosamente la competencia externa implícita en el inminente Tratado de Libre Comercio con América del Norte. Sin embargo, estos intentos no fueron suficientes para revertir el peso de la racionalidad con 
respecto a los valores, y la conversión de la tierra a manos privadas mostró avances escasos.

La conservación de la racionalidad con respecto a los valores también llevó al fracaso las intenciones jurídicas de recapitalización del campo. Para nadie es un secreto que el minifundio es uno de los principales obstáculos para alcanzar escalas de producción que posibiliten la introducción del progreso técnico y de capital, así como para elevar la productividad agropecuaria. Por tal razón, la modificación constitucional prescribía la posibilidad de asociación entre tierras y entre este factor y el capital. No obstante, de nuevo la falta de adaptación a las circunstancias nacionales echó por la borda el proyecto: en un contexto internacional de depresión de precios agropecuarios, la única vía para que el capital se involucrara en este tipo de actividades era la exportación, pues en el mercado interno imperaba la imposibilidad de competir con las importaciones; pero para el otro socio -el campesino-, el mercado exportador demanda una lógica que le es ajena, sino es que adversa: la producción debe tener como primer destino al consumo, y los excedentes, el mercado interno. Este caso evidencia, de nuevo, cómo las recetas modernizadoras absolutas, sin adaptación a las circunstancias del mosaico nacional, producen resultados muy diferentes a los esperados.

Tesis 11. En la medida en que en el campo la heterogeneidad estructural y la diversidad cultural son más acentuadas, la intervención del Estado debe desplegar una politica económica y agropecuaria que implique un tratamiento especial a este sector y a la gama diversa de segmentos económicos y sociales que lo conforman. Una primera directriz consiste en la revisión de las secciones agropecuarias de los tratados internacionales de comercio, a fin de que los cultivos más sensibles para la economía campesina $y$, en menor medida, los orientados al mercado interno sean protegidos de la competencia internacional. Asimismo, las estrategias de asociación entre campesinos y agentes empresariales deben fincarse en el aprovechamiento y consolidación de las formas de organización campesina, y no obligarlas a su desaparición. En cambio, la agricultura empresarial debe ser sometida a la lógica de la competencia, pero con apoyos que habiliten a estos productores a enfrentar la competencia internacional en igualdad de condiciones. 
vi) El modelo tiende a generar una mayor polarización del desarrollo regional. La orientación de la economía hacia el exterior ha empezado a ahondar las diferencias regionales, que hasta la fecha han prevalecido en nuestro país. La exportación manufacturera, pivote del crecimiento económico, ha propiciado que el dinamismo económico tienda localizarse en las frontera norte y en los puertos, así como en aquellas regiones que habían consolidado una cierta base industrial. En el otro polo, las regiones marginadas y las orientadas a abastecer el mercado interno tienden a mostrar un rezago, que difícilmente podrán remontar sin la intervención compensatoria del Estado.

No obstante, una política regional compensatoria enfrenta un reto político de enormes proporciones. La insurgencia de las regiones, abanderada por las más prósperas, ha conducido a un reclamo federalista que no sólo se opone al centralismo tradicional, sino que además adquiere matices reivindicativos que amenazan cualquier política que actúe con un sentido redistributivo a favor de las regiones más atrasadas. Más específicamente, las regiones más ricas reclaman una canalización de recursos fiscales inclinada hacia las que más contribuyen al erario público. De consolidarse esta tendencia, la polarización regional que entraña la propia dinámica del modelo se acentuará. La consecuencia de esta visión es la formalización de un país regionalmente escindido, que puede poner en riesgo la integridad territorial o, en el mejor de los casos, la activación de una mecánica que prescinda de la solidaridad entre los mexicanos.

\subsection{Neoliberalismo, desigualdad y cohesión social}

El bienestar de la persona humana es —o al menos debe ser- el objetivo de todo modelo económico y sentido último de la intervención estatal. En la lógica pura del neoliberalismo, el bienestar social e individual es una consecuencia de las fuerzas ciegas del mercado, que dejadas en plena libertad se encargan de crear la riqueza y de distribuirla con la mejor de las justicias. Sin embargo, después de las promesas, asoman las decepciones: la política neoliberal ha ensanchado las disparidades en la distribución del ingreso, ha generado una mayor concentración de la riqueza y ha aumentado la pobreza, sobre todo la extrema, tanto en términos absolutos como relativos. Estos son los hechos. Las explicaciones apologéticas demandan tiempo suficiente para que las reformas neoliberales rindan los frutos esperados y los pobres puedan in- 
gresar a la tierra prometida. De tratarse de otro asunto, podríamos esperar la recompensa del sacrificio; pero se trata de temas y prácticas que involucran el dolor de millones de mexicanos, frente al cual cualquier discurso sobre la globalización, la competitividad y la eficiencia se desvanece, a menos que la indiferencia impere y el cinismo arraigue.

En términos puros, el neoliberalismo prescinde de una política social destinada a alterar la distribución del ingreso y a aliviar la pobreza: el bienestar es, ante todo, responsabilidad individual, mientras la dinámica del mercado se encarga de equiparar las productividades marginales y, por este conducto, a anular las disparidades sustanciales entre los factores de la producción. La falla de este paradigma es común a toda visión liberal: el supuesto de que se parte de una sociedad en la que prevalece una igualdad original entre los miembros de la sociedad; así, la diferenciación social es fruto exclusivo del esfuerzo personal.

El problema emerge cuando la política neoliberal pretende desatar las fuerzas del mercado y entronizar el individualismo en una sociedad que, como la mexicana, está signada estructuralmente por la desigualdad. Entonces los beneficios del mercado tienden a concentrarse en los más aventajados y en los que están en mejores condiciones para sortear con éxito los retos económicos y humanos, que plantea el funcionamiento competitivo. Entonces el mercado dista de generar y de difundir automáticamente el bienestar social: quienes se encuentran en desventaja para enfrentar las lides competitivas perpetuarán su condición y, en el peor de los casos, se mantendrán marginados del proceso social. Cuando esto sucede se pone en riesgo la cohesión social, pues para estos grupos se cancelan las expectativas de un futuro mejor.

En este sentido, si bien el papel del mercado es insoslayable en la procuración de una mejor calidad de vida, es insuficiente para garantizar que sus beneficios amparen al conjunto de la población, cuando existen amplios segmentos sin oportunidades para desplegar esfuerzos que prometan redituar en el curso de su vida. La intervención del Estado, sobre todo a través del gasto social, deviene indispensable para revertir esa desigualdad original y para redistribuir el ingreso, no por vías fiscales, sino mediante la redistribución de oportunidades. Tal política debe destinarse a habilitar, bajo un principio de subsidiaridad, a los menos aventajados hasta que estén en posibilidades de competir en los mercados (Rawls, 1970). Esto implica invertir en las personas, de 
tal forma que desarrollen sus habilidades para conseguir empleos y para estimular, en su caso, vocaciones y aptitudes empresariales; generar oportunidades de ingresos a través de proyectos productivos, asistencia técnica, apertura de canales de comercialización y dotaciones iniciales de capital. La inversión en capital humano puede convertirse en el eje de una política social compatible con un esquema de crecimiento acotado por la globalización y la disciplina que sobre la política pública impone el mercado. No solamente habilita a la gente para aprovechar oportunidades, sino que se convierte en un generador de éstas al propiciar un crecimiento más alto y sostenido, pues estimula la competitividad y posibilita el afianzamiento de la cultura ciudadana, consustancial a la democracia, sin la cual difícilmente los beneficios del progreso técnico alcanzarán a los más desprotegidos.

En un esquema así, el gasto social se vuelve el principal instrumento de distribución del ingreso y de combate a la pobreza. La vía tributaria con fines distributivos resulta contrapoducente en un país como México, en la medida en que propende a inhibir el ahorro y la inversión, que son unas de las fuentes más importantes de generación de oportunidades para quienes aspiran insertarse en los mercados laborales y para quienes deciden ejercer su vocación y habilidades empresariales. En este sentido, el financiamiento del gasto público debe recaer en esquemas esencialmente recaudatorios - como el Impuesto al Valor Agregadoy promotores de la inversión y el ahorro, y dejar que sea el gasto el que revierta su potencial rasgo regresivo.

Tesis 12. El mercado es insustituible como mecanismo privilegiado de generación de riqueza, pero insuficiente para generar bienestar social. La politica distributiva y de combate a la pobreza debe centrarse en la inversión en capital humano, lo que supone redistribuir oportunidades. La inversión en capital humano no solamente abre oportunidades para los menos aventajados, sino que también constituye uno de los factores claves en el crecimiento económico y la competitividad internacional.

Tesis 13. La politica distributiva del ingreso a través de la distribución de oportunidades debe descansar en el gasto público y no en estrategias tributarias, que acaban por cancelar esas oportunidades. La politica de ingresos públicos debe ser privilegiadamente recaudatoria y promotora; estas dos condiciones son difícilmente compatibles con los propósitos distributivos tradicionales en esa política de ingresos. 
En México, el neoliberalismo ha desplegado una política social que no sólo corre al margen de la política económica, sino que permanece subordinada a ella en el orden de prioridades gubernamentales; es un lujo del que se goza siempre y cuando no arriesgue los equilibrios macroeconómicos y la eficiencia del sistema económico. Pero en última instancia, la instrumentación de una política social orientada a la formación del capital humano (Progresa), a la infraestructura social básica (Ramo 33) y la promoción de proyectos productivos ha obedecido a la necesidad de la élite neoliberal de conservar el consenso necesario para evitar descalabros sociales y trastornos electorales. A pesar de que estos programas exhiben diseños bien elaborados, su adecuada operación padece permanentemente el conflicto entre los objetivos propios de los programas y las necesidades consensuales de un gobierno que aprovecha su impacto electoral. Este conflicto ha derivado en resultados infructuosos y en desviaciones recurrentes que ahondan las dificultades que, desde un punto de vista económico, impide traducir el crecimiento en bienestar.

El mensaje es claro: el éxito de la política social destinada a la redistribución de oportunidades está altamente determinado por el contexto y la estructura política en la que se desenvuelve; mientras no se destierren de la vida comunitaria las prácticas políticas de cooptación, ninguna política social tendrá éxito.

Tesis 14. La política social y la económica no deben operar separadamente, ni desplegarse bajos criterios en los que una trabaje subordinadamente a la otra. Los objetivos de la política social deben trabajar a favor de la económica, y los de ésta a favor de la social. Ambas deben fundirse en una sola: la política de bienestar de la persona humana.

Tesis 15. La politica social de redistribución de oportunidades no es ajena al contexto político social en el que se ejecuta, y sólo tendrá éxito cuando la democracia arraigue en la vida comunitaria y cuando se destierren prácticas clientelares, asociadas al sistema tradicional de dominación.

\section{Corolario}

El regreso a un intervencionismo estatal de viejo cuño es política y técnicamente inviable. El intento neoliberal de implantar un proceso modernizador fincado en una racionalidad única y uniformadora es incapaz de solucionar los problemas nacionales, porque al combinarse con una estructura económica y social he- 
terogénea, arroja resultados que distorsionan el funcionamiento económico y lo alejan del camino que conduce al bienestar y a la justicia social. Por tal razón, la intervención del Estado debe ser orientada hacia la conformación de un modelo propio de desarrollo, que recoja y adapte la racionalidad del mercado a las necesidades, valores y prácticas de los mexicanos.

\section{Bibliografía}

Benítez, Fernando (1980), Lázaro Cárdenas y la Revolución Mexicana, México, Fondo de Cultura Económica.

Braiding (1980), Los orígenes del nacionalismo mexicano, México, Era.

Bresser Pereira, Luis Carlos (1999), La reconstrucción del Estado en América Latina, Revista de la Cepal, octubre.

Burki, J. y Perry G. (1998), Beyond the Washington consensus: institutions matter, World Bank, Latin American and Caribbeans Studies.

Buttiglione (1990), La tercera vía y la crisis de las ideologías, ITESM, Campus Ciudad de México, Mimeo.

Car, Barry (1973), El movimiento obrero y la Revolución Mexicana, México, Sep-Setentas.

Casar, J. (1982), “Ciclos económicos en la industria y sustitución de importaciones: 1950-1980”, en Economía Mexicana, México, núm. 4.

Córdova, A. (1974), La formación del poder político en México, México, Era.

Cosío, Villegas (1976), El estilo personal de gobernar, México, Joaquín Mórtiz.

Dertouzos et al. (1989), Made in América: Regaining the Productive Edge, Cambridge, Massachusetts, MIT Press. 
Fajnzylber, Fernando (1983), La industrialización trunca de América Latina, México, Nueva Imagen.

Giddens, A. (1999), La tercera vía, Barcelona, Taurus.

Hernández Rodríguez (1988), Empresarios, Banca y Estado. El conflicto durante el gobierno de José López Portillo, Miguel Porrúa, México.

Lusting, N. (1981), Crecimiento y distribución del ingreso en México, México, El Colegio de México.

Millán, Henio (1997), "Penetración de importaciones y dinamismo exportador”, Investigación Económica, núm. 221, julio-septiembre.

Millán, Henio (1998), Neoliberalismo y transición en México, Zinacantepec, México, El Colegio Mexiquense, A.C.

Norton, Douglas (1995), Instituciones, cambio institucional y desempeño económico, México, Fondo de Cultura Económica.

O’Donell, G. (1979), “Tensions in the bureaucratic-authoritarian state and the question of democracy", en D. Coller, The new authoritarianism in Latin America, Princeton, Princeton University Press.

Pinton, A. (1973), "El modelo de desarrollo reciente", en Raíces estructurales de la inflación, México, Lecturas núm. 3, Fondo de Cultura Económica.

Rawls, John (1970), Teoría de la justicia, México, Fondo de Cultura Económica.

Rodríguez, Octavio (1980), La teoría del subdesarrollo de la Cepal, México, Siglo XXI.

Tavares, M. C. (1980), "La industrialización de importaciones como modelo de desarrollo reciente", en De la sustitución de importaciones al capital financiero, México, Fondo de Cultura Económica. 
756 Millán, H.: Estado y modernización: quince tesis y un corolario para México

Tavares, M. C. (1982), "Problemas de la industrialización avanzada en capitalismos tardíos y periféricos", en Economía de América Latina, México, CIDE, núm. 6.

Thurow, Lester (1992), La guerra del siglo XXI, Buenos Aires, Vergara.

Enviado: 22 de agosto de 2000. Aceptado: 13 de marzo de 2001. 